\title{
Silent rupture of unscarred uterus at 32 weeks: Case reports
}

\author{
Divya $^{1, *}$, Sarita Singh ${ }^{2}$, Achla Batra ${ }^{3}$, Sunita Malik ${ }^{4}$, Rupali Dewan ${ }^{5}$ \\ ${ }^{1}$ Senior Resident, ${ }^{2}$ Assistant Professor, ${ }^{3,4,5}$ Professor and Consultant, Dept. of Obstetrics and Gynecology \\ Vardhman Mahavir Medical College and Safdarjung Hospital, New Delhi, India
}

*Corresponding Author:

Email: divambbs@gmail.com

Received: $19^{\text {th }}$ June, 2018

Accepted: $31^{\text {st }}$ July, 2018

\begin{abstract}
Introduction: Rupture in an unscarred uterus prior to onset of labor in third trimester is a rare event and very few cases have been reported in literature so far.

Case Report 1: We describe a case of a primigravida who presented in emergency with pain abdomen with placenta praevia and severe oligominos. An ultrasound was conducted which reported bicornuate unicollis uterus with single live foetus $33+4$ weeks having severe oligohydromnios $(\mathrm{AFI}=2)$ with placenta anterior and reaching upto internal os in one cornua, the other cornua was empty. A MRI was conducted, which was also inconclusive. She was taken up for laprotomy, peroperatively pregnancy was present in left horn of uterus which had ruptured with intact amniotic sac and was covered with omentum, the placenta was covering the lower half of the left horn and the right horn looked like normal uterus and was empty. The omentum was carefully separated and baby that was delivered weighed $700 \mathrm{gms}$. The left horn was excised and then uterus was closed in layers. Patient was followed up for 6 months, mother was doing well, though baby was $5 \mathrm{~kg}$ which was less than the weight for that age and had slow developmental milestones.

Case Report 2: Our second case was a 30 years old gravida 5, para 2, abortion 2 woman with 8 months amenorrhea. She was referred with chief complaint of pain abdomen. On examination, she looked almost stable. Even though she was pale; vital signs were within normal parameters. An ultrasound was conducted which showed single live intrauterine foetus $29^{+2}$ weeks with absent liquor with placenta praevia with placenta acreta. Emergency laprotomy was decided in view of placenta acreta. It was found to be an abdominal pregnancy. Amnion along with omentum and blood clot matting sac like structure sitting over the fundus with placenta perforating the fundus small incision was given at the fundus and baby weighing $1.15 \mathrm{~kg}$ delivered through it. Placenta did not separate and so decision of hysterectomy taken.

Conclusion: Rupture in a non laboring unscarred uterus is a very rare condition and needs high index of suspicion for diagnosis it should be kept in differential diagnosis of pregnancy with abdominal pain of any degree.
\end{abstract}

Keywords: Advanced abdominal pregnancy, Ectopic pregnancy, Silent rupture.

\section{Summary}

Abdominal pregnancy is an uncommon form of ectopic pregnancy with high risk of morbidity and mortality for both the mother and the foetus. Even rarer is a case of silent rupture in an unscarred uterus and foetus being alive. Two cases of abdominal pregnancy after silent rupture which resulted in live healthy newborns at Safdarjung Hospital in Delhi India is presented.

\section{Introduction}

Ectopic pregnancy is rare and has an incidence of 1$2 \%$ of all pregnancies reported nearly $95 \%$ of implantation occurs in the fallopian tube. Abdominal pregnancies represents only $1 \%$ of all the ectopic pregnancies. Abdominal pregnancy ranges between 1: 10,000 pregnancies to 1:30,000 pregnancies. ${ }^{1}$ These pregnancies do not reach to third trimester and mostly ends in the extraction of a dead foetus It is also associated with very high incidence of congenital malformations. Spontaneous rupture of uterus has been report in labouring pregnant women due to external injuries or in scarred uterus. Although, spontaneous rupture in an unscarred uterus prior to onset of labor in third trimester is an extremely rare event.

\section{Case Report 1}

We describe a case of a primigravida with 8 month amenorrhea who was referred in emergency with pain abdomen ultrasound showing placenta praevia and severe oligominos. Patient's vitals were stable and uterus was relaxed corresponding to 28 weeks gestation with no vaginal bleeding. An ultrasound was conducted which showed bicornuate unicollis uterus with single live foetus $33+4$ weeks having severe oligohydromnios $(\mathrm{AFI}=2)$ with placenta anterior and reaching upto internal os in one cornua, the other cornua was empty with no findings suggestive of rupture The patient was admitted and corticosteroids were given for lung maturity. A MRI was conducted but was inconclusive to differentiate between a ruptured horn or an abdominal pregnancy. She was taken up for laprotomy, preoperatively pregnancy was present in left horn of uterus which had fundal rupture with intact amniotic sac The sac was only revealed after dissecting omentum which had completely covered it, the placenta was covering the lower half of the left horn and the right horn looked like normal uterus and was empty. (Fig. $1 \& 2$ ). The omentum was carefully separated and baby that was delivered weighed 700gms. The left horn was excised with left sided fallopian tube. The right horn of uterus 
and right fallopian tube were left in situ and the defect was closed in layers The postop period was uneventful. Patient and neonate was followed up from birth till 6 months, mother was doing well till date, though baby was $5 \mathrm{~kg}$ which was less than the weight for that age and had slow developmental milestones. (Fig. 3)

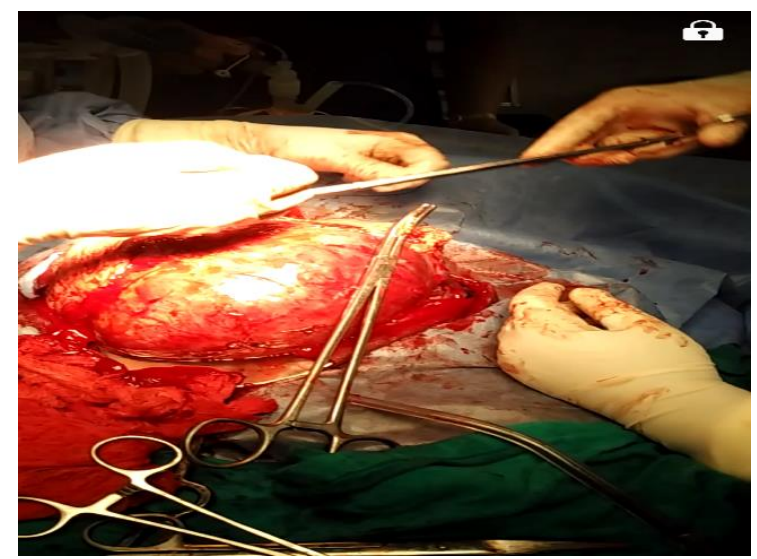

Fig. 1: Ruptured horn covered by peritoneum and omentum containing the $\mathrm{g}$ sac and the baby (case report 1)

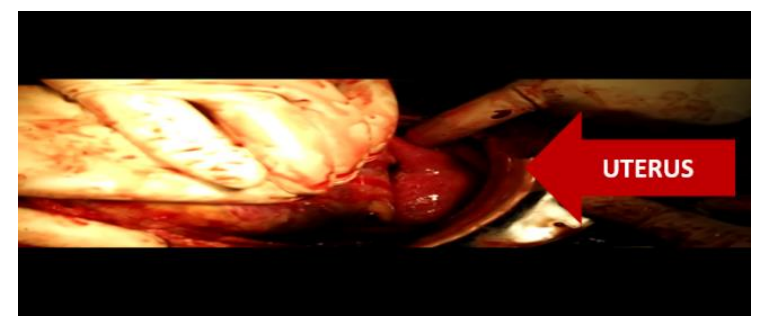

Fig. 2: Right horn uterus (case report 1)

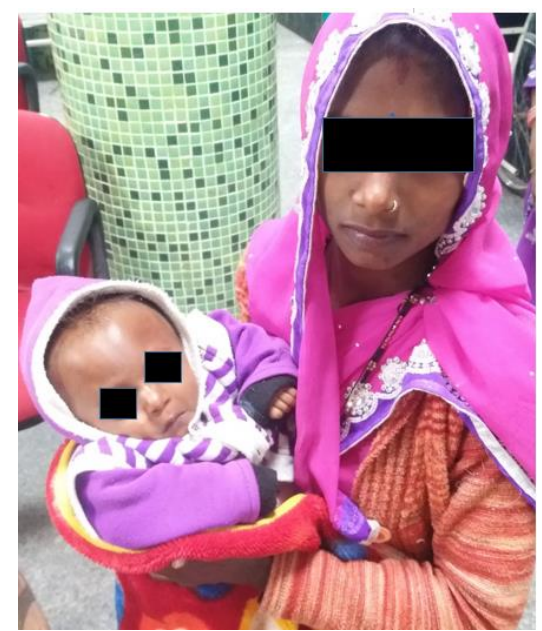

Fig. 3: Picture of baby and mother at 6 months follow up (case report 1)

\section{Case Report 2}

A 31- year- old woman, Gravida 5 Para 2 live 2 abortion 2, with 8 months amenorrhea was referred with severe abdominal pain. An ultrasound was conducted which showed single live intrauterine foetus $29^{+2}$ weeks with absent liquor with placenta praevia and accrete MRI was done and it showed an intraabdominal pregnancy foetus lying separate from the uterus (Fig. 4). On examination, she looked pale but generally stable. The abdominal examination revealed soft distension with symphysio-fundal height of $32 \mathrm{~cm}$, breech, foetal heart rate of 136 beats per minute and no uterine contractions but with absent bowel sounds.

The haemoglobin level was $6.9 \mathrm{gm} / \mathrm{dl}$. She was taken up for laparotomy in view of placenta accreta with intestinal obstruction or query perforation. At laparotomy it was found that it is an abdominal pregnancy. Amnion along with omentum and blood clot matting sac like structure was sitting over the fundus with placenta perforating the fundus. Small incision was given at the fundus and baby weighing $1.15 \mathrm{~kg}$ delivered through it. Placenta did not separate and so decision of hysterectomy taken. (Fig. $5 \& 6$ ).

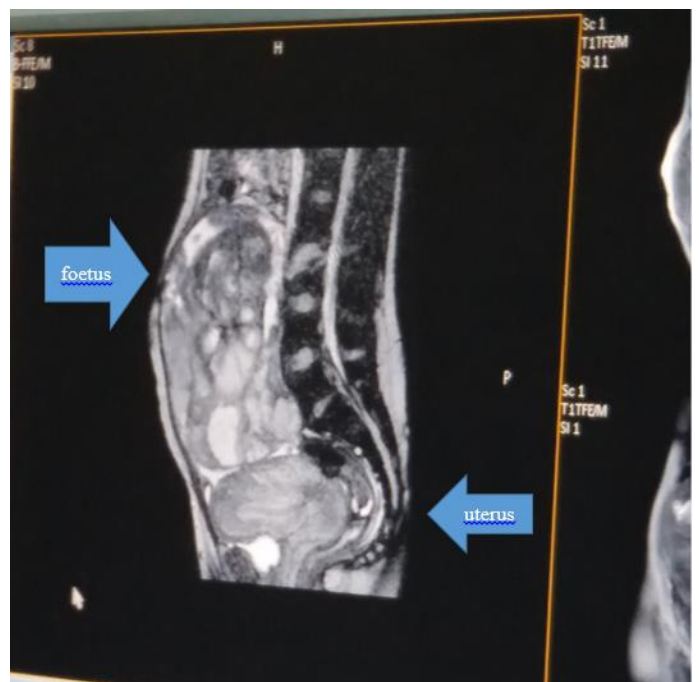

Fig 4. Saggital section of MRI showing an intrabdominal pregnancy (case report 2)

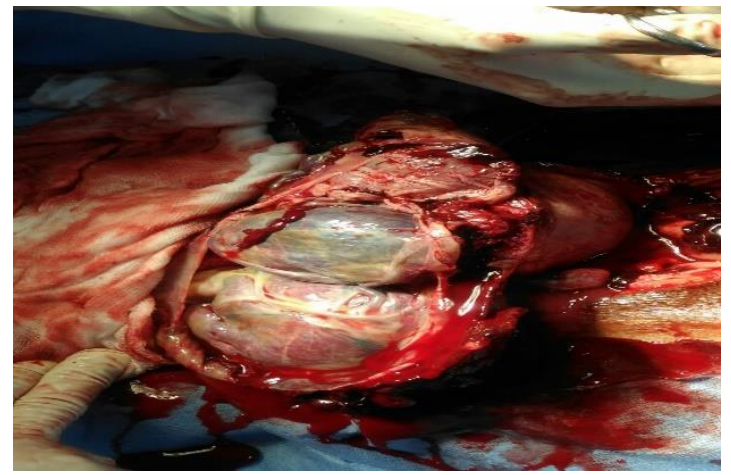

Fig. 5: Foetus visible through the rent in the fundus after extending the incision (Case Report 2) 


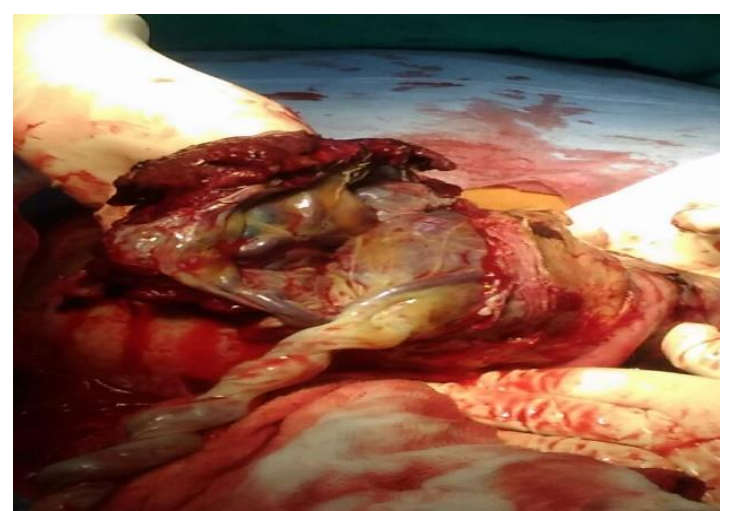

Fig. 6: After extraction of foetus placent can be seen lying inside the uterus (Case Report 2)

\section{Discussion}

Advanced abdominal pregnancy is extremely uncommon. In a review at the Komfo Anokye Teaching Hospital, Opare-Addo et al reported an incidence of 1:1320 deliveries ${ }^{2}$ while Amirtha et al cited 1:25000 deliveries. ${ }^{3}$ Abdominal pregnancies usually results secondary from aborted or ruptured tubal ectopic pregnancy. Abdominal pregnancy is only found in $1.4 \%$ of all ectopic pregnancies. ${ }^{1}$ The incidence of abdominal pregnancy ranges between 1:10,000 pregnancies to 1:30, 000 pregnancies. ${ }^{1}$ The occurrence is found to be high in women of developing nations. ${ }^{2}$ The reason to this can be attributed to low socioeconomic status, high rate of pelvic inflammatory disease or pelvic infection, history of infertility, tubal sterilization, tubal reconstruction surgery, pregnancy with intra uterine device. ${ }^{2}$ Compared to tubal and intrauterine pregnancies, the risk of dying because of abdominal pregnancy is 7.7 times more than the tubal pregnancy and 90 times greater than an intrauterine pregnancy. ${ }^{2}$ The maternal mortality may range from $0.5 \%$ to $18 \%$ and perinatal mortality rate is $40-95 \% .^{2}$

Rupture of unscarred uterus is an extremely rare event having an incidence of 1 in 16,000 deliveries. ${ }^{4}$ The cause attributed in the reported cases are external injuries, induction of labor, multiparity, cephalo-pelvic disproportion, placenta accreta, fundal pressure, abruption, cocaine abuse and history of intrauterine intervention causing perforation.

However, the diagnosis is generally made during laparotomies performed for various indications. In our first case diagnosis of ruptured horn was not confirmed even on MRI, which highlights the fact, that because of its rare incidence, even the radiologists find it a diagnostic dilemma. What makes it unique, is the silent rupture which did not cause any discomfort and went unnoticed by the patient. The probable sequence of events can only be hypothesized, the slow fundal rupture may have occurred in first or second trimester which was sealed off by the omentum forming a supportive layer over the amniotic sac and preventing its rupture and ousting of fetus into the peritoneal cavity. Omentum due to its rich blood supply provided umbrella cover on the ruptured site which accommodated with the advancing gestation. In the second case rupture could have occured due to weakening of the uterine myometrium, which became more profound in the third trimester due to invasion of the myometrium by the placenta percreta leading to silent rupture.

The uncertainity of diagnosis and high suspicion of abdominal pregnancy, landed both the patient in laprotomy. Whether the omentum would have helped the furthur growth of the fetus beyond 34 weeks if the pregnancy was allowed to continue, the available literature gives no supportive evidence. . $^{5-9}$

In literature, only three cases of silent rupture in unscarred, relaxed uterus have been reported. In one of the reported cases, emergency laparotomy was planned when maternal condition detoriated after vaginal delivery of the stillborn baby by forceps, rupture uterus was found behind the cornual structures. ${ }^{1}$ The second reported case had a tear above the insertion of right uterosacral ligament and the baby was born by emergency lower segment Caesarean section and tear repaired later. ${ }^{2}$

In the third case reported laparotomy was done for deteriorating maternal condition and foetal demise and it was post failed induction. There was a tear in posterior uterine wall through which foetus along with amniotic sac had silently expelled into the abdominal cavity. Uterine contour was falsely maintained due to intact amniotic sac making the diagnosis of uterine rupture difficult. $^{3}$

\section{Conclusion}

This case accentuates the fact that uterine rupture can present in many ways and high vigilance is required for timely intervention to prevent maternal morbidity and mortality.

\section{References}

1. Isah A Y, Ahmed Y, Nwobodo E I, Ekele B A. Abdominal pregnancy with a full term live foetus: case report. Ann Afr Med. 2008;7:198-9.

2. Badria L, Amarin Z, Jaradat A, Zahawi H, Gharaibeh A. Full-term viable abdominal pregnancy. A case report and review. Arch Gynaecol Obstet. 2003;268(4):340-342.

3. Opare-Addo HS, Deganus S. Advanced abdominal pregnancy: a study of 13 consecutive cases seen in 1993 and 1994 at Komfo Anokye Teaching Hospital, Kumasi, Ghana. Afr J Reprod Health. 2000 Apr;4(1):28-39.

4. Amritha B, Sumangali T, Priya B, Deepak S, Rai S. A rare case of term viable secondary abdominal pregnancy following rupture of a rudimentary horn. A case report. $J$ Med case reports. 2009;3:38.

5. Karat LS. Viable Abdominal Pregnancy. J Obstet Gynecol India. 2007;57(2):169-170.

6. Cunningham F, Gant N, Leveno K, et al. Williams Obstetrics. 21. Mcgraw-Hill; 2001. Ectopic Pregnancy; pp. 899-902.

7. Jianping Z, Fen L, Qiu S. Full-Term Abdominal Pregnancy. A Case Report and Review of the Literature. Gynecol Obstet Invest. 2008;65(2):139-141. 
8. Teng H, Kumar G, Ramli N. A viable secondary intraabdominal pregnancy resulting from rupture of uterine scar: role of MRI. Br J Radiol. 2007;80:134-136.

9. Kun K, Wong P, Ho M, Tai C, Ng K. Abdominal pregnancy presenting as a missed abortion at 16 weeks gestation. Hong Kong Med J. 2000;6(4):425-427.

How to cite this article: Divya, Singh S, Batra A, Malik S, Dewan R. Silent rupture of unscarred uterus at 32 weeks: Case reports. Ind J Obstet Gynecol Res. 2018;5(3):429-432. 